\title{
Cidades como pessoas: uma genealogia das formulações de Richard Morse sobre as cidades na América Latina
}

\author{
Cities as people: a geneology of the formulations of Richard Morse on cities in Latin
}

America

\author{
Beatriz Helena Domingues* \\ Doutorado em Engenharia de Produção \\ Professora do Departamento de História \\ da Universidade Federal de Juiz de Fora \\ biahdomingues@gmail.com
}

Resumo: A proposta deste ensaio é analisar, cronologicamente, algumas formulações do historiador norte-americano Richard Morse (1922-2001) sobre a problemática das cidades na América Latina e no Brasil. Começa pelos estudos do jovem Morse sobre São Paulo nos anos 1940 e 1950, passa pelos trabalhos sobre as cidades latino-americanas nos anos $1960 \mathrm{e}$ 1970, e finaliza com os ensaios da maturidade, em especial "Cidades como pessoas", de 1995. Estão em foco os ensaios nos quais as cidades são entendidas como pessoas e/ou como representantes da influência filosofia tomista e neotomista na América Latina e no Brasil.

Palavras-chave: Richard Morse; Cidades na América Latina; São Paulo; Tomismo.

\begin{abstract}
The purpose of this essay is to analyze, chronologically, some formulations by the American historian Richard Morse (1922-2001) on the subject of cities in Latin America and Brazil. It begins with the studies by the young Morse about São Paulo in the 1940s and 1950s, continues with his works on Latin American cities in the 1960s and 1970s, and ends with the maturity essays, especially "Cities as people", in 1995. The focus will be on the essays in which cities are understood as people and/or as representatives of the influence of Thomistic and neo-Thomistic philosophy in Latin America and Brazil.
\end{abstract}

Keywords: Richard Morse; Cities in Latin America; São Paulo; Thomism.

\footnotetext{
* Este ensaio é resultado parcial da pesquisa financiada pela FAPEMIG. .
} 


\section{Introdução}

A proposta deste ensaio é analisar, cronologicamente, algumas formulações de A temática urbana na América Latina ocupa um papel central na obra do historiador norteamericano Richard Morse desde a juventude até a maturidade. Como em outros temas que lhe foram caros, as referências à literatura, filosofia e sociologia são recorrentes, bem como as comparações entre partes da América Latina, ou entre ela e os Estados Unidos. Embora historiador por profissão, Morse (1922-2001) não é facilmente classificável. No campo da história, eu diria que ele tem afinidades com a denominada História Cultural ou História Intelectual.

Ainda que a metodologia comparada - que é a adotada por Morse - possa ser direcionada para campos tão diferentes como a história econômica, política ou literária, ele elegeu a literatura como campo privilegiado para seus estudos de história urbana desde início de sua carreira.

Já em sua tese de doutorado sobre São Paulo, escrita no fim da década de 1940, até as formulações mais abrangentes e filosóficas da maturidade, sua obra caracterizouse por ensaios, sempre comparativos, entre as Américas ibérica e anglo-saxônica, através de seus escritores favoritos em ambas. Talvez tenha sido isso o que o levou a procurar, assim que chegou a São Paulo para pesquisar sobre a cidade, os poetas e escritores, antes de percorrer seus arquivos. E, mesmo depois de remexer nas "fontes tradicionais", permaneceu atraído por aquelas não tão usais. Desde então, até a maturidade, a abordagem das cidades foi associada ao interesse do autor Morse em realçar e analisar a influência da influência tomista na cultura e na história urbana latino-americana. E o fez de uma forma bastante inovadora e singular: considerando essas cidades como pessoas, e ao mesmo tempo como arenas culturais de vanguarda, precisamente por serem periféricas ao invés de apesar de serem periféricas.

Na década de 1960 sua análise da temática urbana - que já nasceu interdisciplinar e comparativa, em grande parte apoiada em Max Weber -, aprofundou o diálogo com a história latino-americana. A partir da década de 1970, ele passou a acentuar as diferenças entre o mundo anglo e o ibero-americano na história, na literatura, na filosofia, nas artes ou simplesmente no comportamento. As décadas de 1980 e 1990 aprofundaram esta abordagem. 
Em 1954 Morse detectara no pensamento de Tomás de Aquino uma chave de leitura fundamental para compreender a história ibérica e a ibero-americana. Chegou a esboçar, naquela ocasião, uma teoria sobre o governo hispano-americano (MORSE, 1954c). Desde então, até a década de 1970, o tema predominante da produção morseana foi a história e a cultura urbana da Hispano-América. É importante, contudo assinalar que seu interesse pelo estudo de cidades começou, nos anos 1940, com a pesquisa de doutorado sobre a história de São Paulo, ainda que o Brasil só tenha aparecido em seus estudos posteriores em parágrafos comparativos com a América hispânica. Em 1972 Morse parecia ter fechado um ciclo de seus estudos urbanos ao teorizar sobre a riqueza das ideias de Tomás de Aquino para abordar a cultura urbana do subcontinente, em um longo ensaio intitulado "Um prolegômeno para a história urbana da América Latina" (MORSE, 1972). Mas, como veremos, ele retomou o tema esporadicamente nas décadas de 1980 e 1990, com abordagens bastante eruditas e sofisticadas que, longe de contradizer as anteriores, certamente as enriqueceu e aprofundou.

A tese de doutorado de Morse sobre São Paulo foi publicada no Brasil, como livro, em 1954, como parte das comemorações dos quatrocentos anos da cidade (MORSE, 1954a). Nesse estudo o autor buscava compreender como a cidade, na qual residiu e pesquisou nos idos de 1940, pôde ter se transformado tão rapidamente de vila, em meados do século XIX, em uma metrópole, em apenas quatro décadas. Mas não era só isso: tratase de uma metrópole ímpar, que a seu ver não perdera seu sentido de comunidade. Daí viria o título de sua tese: De comunidade a metrópole: biografia de São Paulo. ${ }^{1}$

Segundo Antonio Candido, o livro já nasceu um clássico, pois, em seu entender, trata-se "certamente do melhor livro sobre esse assunto difícil, quase perigoso devido à mobilidade por vezes desnorteante do objeto" (CANDIDO, 1988: 11). A arquiteta Ana Cláudia Castro pondera, contudo, que se tratou de "um clássico desconhecido", não porque discorde de Candido que se trata do melhor livro sobre a história de São Paulo. Pelo contrário, foi apenas por constatar, em sua pesquisa de doutorado sobre o livro, que,

\footnotetext{
${ }^{1}$ A versão em inglês do livro sobre São Paulo foi publicada em 1958. From Community to Metropolis: A Biography of São Paulo, Brazil. Gainesville: University of Florida Press, 1958. Ou seja, com o título que Morse escolheu: biografia e não história. Outro ensaio do mesmo período lidando com a temática é: São Paulo in the Nineteenth Century: Economic Roots of the Metropolis, Inter-American Economic Affairs, V, 3 (Winter, 1951) pp. 24-37.
} 
embora muito citado, poucos estudiosos de fato o discutem (CASTRO, 2013; 2010). Eu tampouco o discuto aqui.

Como as sintonias que persigo entre os autores encontram-se no campo cultural, optei por centrar minha análise em um ensaio publicado, no mesmo ano, na Hispanic American Historical Review, intitulado "São Paulo since Independence: A Cultural Interpretation", que seguia o mesmo esquema cronológico do livro, porém focando quase que exclusivamente nos aspectos culturais que considerava mais elucidativos para explicar a passagem da comunidade à metrópole (MORSE, 1954b: 419-444). ${ }^{2}$ Nele, Morse esboça uma tese muito interessante, que foi aprofundada em 1984 em "Cidades periféricas como arenas culturais": a produção cultural de uma cidade ou de um país não está diretamente condicionada a seu desenvolvimento econômico, material. Algumas vezes pode-se mesmo encontrar essa equação invertida (MORSE, 1995b). ${ }^{3}$ A condição de periferia pode conduzir certas cidades a tornarem-se arenas culturais mais instigantes e criativas que aquelas do centro. Foi o que aconteceu, em seu entender, com o Modernismo na Rússia, no Brasil e na América Latina na segunda década do século XX, em grande medida devido à crise europeia que se seguiu à Primeira Guerra Mundial.

As fontes de Morse são pouco convencionais: ouvir as vozes da cidade da boca dos ícones dos dois movimentos literários que considerou mais significativos - o Romantismo e o Modernismo - representados principalmente, ainda que não exclusivamente, por Álvares de Azevedo, Castro Alves, Machado de Assis, Mário e Oswald de Andrade e Lasar Segall. Os poemas de Álvares de Azevedo e de Castro Alves lhe mostravam uma São Paulo bem singular, certamente muito mais pobre que o Rio de Janeiro imperial ou as esplendorosas cidades barrocas de Minas Gerais ou Bahia.

Uma de suas hipóteses, segundo nos conta, foi fruto de uma conversa com Lasar Segall sobre a influência do clima e das cores da cidade em sua vida cultural. Certamente as tradições de São Paulo não ostentam a riqueza e a panóplia da Bahia colonial, ou uma exótica cultura popular africana ou indígena, nem a suntuosidade da corte no Rio de Janeiro. Diferentemente das três, a configuração física de São Paulo parecia "moderada" e "neutra", e a "garoa", um traço distintivo dessa cidade que não seria nem tropical nem

\footnotetext{
${ }^{2} \mathrm{O}$ critério de escolha foi a recente tradução desse texto para o português, por Maria Bitarello, e consta de uma antologia por mim organizada, intitulada "Richard Morse: cidades e cultura política nas Américas", com publicação prevista para 2016 pela Editora da UFMG. Esse foi também o caso de "Algumas características da história urbana da América Latina" (1962), e "Prolegômenos para a história urbana da América Latina" (1972) e de "Cidades como pessoas" de 1992, que serão discutidos a seguir.

${ }^{3}$ A publicação original em inglês foi em 1984 e em espanhol em 1985.
} 
temperada, teria contribuído para que alguns românticos a comparassem com a Londres de Byron. A seu ver, contudo, o florescimento estudantil em São Paulo, ocorrido por volta de 1845-55, favoreceu o surgimento de diferentes tipos de românticos. Em alguns poetas do movimento, Morse perscruta o teor de vida citadina que eles representam. O par de poetas selecionado para "escutar" a São Paulo de então foi Álvares de Azevedo (18311852) e Castro Alves (1847-1871).

As apreensões de Álvares de Azevedo com o crescimento desordenado de São Paulo são comparadas com outras visões cautelosas, como uma carta redigida por Ricardo Daunt, em 1856. Nascido irlandês, Daunt tornou-se um católico conservador brasileiro, estabelecendo-se na tradicional cidade de Itu, no interior do estado, de onde reprovava veementemente os novos rumos da vida em São Paulo. Morse se identifica com as apreensões de ambos, e equipara as críticas de Daunt àquelas de Alexis de Tocqueville (1805-1859) ou de John Calhoun (1782-1850) aos Estados Unidos (MORSE, 1954b, 442).

Há muitos que querem ver São Paulo crescer em riqueza e fazer enormes progressos, mas poucos são os que se preocupam se isto vai ocorrer à custa de perda do caráter paulista... Eu, entretanto, sem querer mascarar meu amor pela Província, não anseio por uma transformação tão rápida (...). Em minha opinião uniformidade de pensamento, costumes, gostos e caráter pressagiam a decadência de qualquer grande império, pois sendo em si mesmo uma coisa forçada e não natural, pode emanar somente de influência indevida da Corte ou de outros centros e é sempre um indício de falta de espírito, de virilidade, em povos então uniformizados que, desta forma, se preparam para o despotismo (GUMBLETON, 1856, apud MORSE 1954b: 427. Grifos da autora). ${ }^{4}$

Já nos escritos de Castro Alves, bem como nos de Rui Barbosa e de Joaquim Nabuco, Morse diagnostica uma impaciência para com a tenacidade da tradição regional e para com os anseios discursivos da geração romântica de Azevedo. Citando o mestre Alan Tate, que marcou sua formação na Columbia University, Morse arrisca sua própria comparação entre os poetas locais e alguns europeus:

\footnotetext{
${ }^{4}$ Carta de Ricardo Gumbleton Daunt para Francisco Inácio Marcondes Homem de Melo, agosto de 1856, Instituo Histórico e Geográfico Brasileiro, lata 8, ms. 148 B (cópia datilografada do original).
} 
Se Álvares de Azevedo é o Shelley que se torna espiritualmente impotente diante de um mundo científico e "cai sobre os espinhos da vida", Castro Alves se inclina a uma solução alternativa. Com a "imaginação bruta e física" de um Tennyson, ele "goza de algo como o otimismo eficiente da ciência, e nos pede que acreditemos que um rearranjo das relações externas de um homem apenas não o tornará um pouco mais confortável, mas também removerá o problema do mal, e inaugurará a perfeição" (MORSE, 1954b: 429). ${ }^{5}$

Acentuo este ponto porque me parece ser exemplar de uma das preocupações que perseguiu Morse durante toda a vida: a crítica do progresso material desprovido da contrapartida espiritual, humana. Sua sintonia com autores que acenam nessa direção dá o tom de sua análise sobre o crescimento econômico da cidade no século XIX, que não foi teria sido acompanhado de uma sofisticação intelectual.

Em seu entender, São Paulo tornou-se uma "arena cultural" apenas com o Modernismo nas primeiras décadas do século XX. Os modernistas retomaram, dos românticos de meados do século XIX, a sintonia com a comunidade que o "virtuosismo" romântico do fim do século havia perdido. A tese de Morse foi, então, que o provincianismo de São Paulo refletiu-se em sua expressão cultural. Sua explicação para isto poderia se confundir com um trecho de Sobrados \& Mucambos, de Gilberto Freyre.

A cidade não herdou dos índios quaisquer artes avançadas e, de mais a mais, não possuía recursos para importar as europeias, nem tinha perspectivas ou disposição para desenvolvê-las localmente em nenhuma medida. Diante dessas limitações, a mais notável façanha talvez tenha sido a arquitetura dos domicílios patriarcais: os sobrados dentro da cidade e as chácaras em seus arredores. Estas casas eram de taipa ou terra batida, jamais do granito que deu ao Rio de Janeiro, a Recife, a Salvador e, até mesmo, a Santos uma compleição urbana europeia. Elas também eram verdadeiramente funcionais, se entendemos o termo como a beleza

\footnotetext{
${ }^{5}$ A forma como Morse vê Álvares de Azevedo e sua geração me parece em sintonia com a que Marshall Berman descreve o que considerava a segunda etapa da modernidade, ou seja, o século XIX. Segundo ele, o mérito dos "modernistas" do século XIX foi ter se encantado e ao mesmo tempo criticado o mundo em rápida transformação ao seu redor. "Todos os grandes modernistas do século XIX atacam esse ambiente, com paixão, e se esforçam para fazê-lo ruir ou explorá-lo a partir do seu interior; apesar disso, todos se sentem surpreendentemente à vontade em meio a isso tudo, sensíveis às novas potencialidades, positivos ainda e suas negações radicais, jocosos e irônicos ainda em seus momentos de mais grave seriedade e profundidade" ( BERMAN, 1982: 18).
} 
despretensiosa decorrente do uso racional de materiais locais e de conhecimento de padrões sociais e da tradição (MORSE, 1954b: 420-421. Grifos da autora). ${ }^{6}$

Embora a metrópole moderna tenha confinado os sobrados e seu estilo de vida ao esquecimento, sua graça e dignidade ainda podiam ser confirmadas, em seu entender, nas primeiras fotografias de São Paulo e de cidades do interior paulista, como Itu e outras ao longo do vale do Paraíba. Mais do que em outras partes do Brasil, a cultura europeia foi, segundo Morse, transfigurada pelo espírito popular nativo, o que deu à futura metrópole uma compleição menos urbanizada do que suas concorrentes nacionais do Rio, Minas Gerais e Bahia.

Sem abdicar de explicações econômicas e sociais, fartamente oferecidas no livro sobre a história de São Paulo, o autor privilegia personagens - viajantes, pensadores, novelistas e poetas - que, desde as últimas décadas do século XIX até as primeiras do século XX, perceberam e expressaram, criticamente, as características da cidade e, em certa medida, do Brasil.

Os primeiros sinais de mudança teriam ocorrido em meados do século XIX, quando "a introvertida comunidade tornou-se centro de atração sobre professores e alunos de diversas partes do país" (MORSE, 1954b: 424). Correspondeu aos anos do Romantismo, durante as décadas de 1840 e 1850, representados especialmente pelo poeta Álvares de Azevedo.

É possível, prossegue ele, que a falta de paisagens ou de um passado memorável tenha produzido, em meados do século, "uma literatura que abordava temas mais latentes e mais difusos que no Norte, onde um autor como o maranhense Gonçalves Dias (18231864) idealizava os costumes sobreviventes do "nobre selvagem" (BANDEIRA, 1946, apud MORSE, 1954b: 425)". Isso talvez explique o porquê de, na São Paulo de fins do século XIX, as grandes realizações dos liberais - a abolição da escravidão e a proclamação da República - terem deixado um vácuo ideológico ao invés de direcionar a atenção para preocupações mais complexas. Morse lamenta apenas que o entusiasmo e clamor pela concretização do progresso material tenham gerado uma espécie de apatia intelectual

\footnotetext{
${ }^{6}$ Esses comentários de Morse se inspiraram em: SAIA, Luís. Carapicuíba (ms., 1938, emprestado pelo autor) e "Notas sobre a arquitetura rural paulista do segundo século", Revista do Serviço do Patrimônio Histórico e Artístico Nacional, 8 (1944), pp. 247-275; BRUNO, Ernani Silva. "Apontamentos sobre a cidade e a casa de São Paulo no século dezenove", Boletim bibliográfico, I, 3 (Abril-Junho, 1944), pp. 99104; Saint-Hilaire, Voyages dans les Provinces de Saint-Paul (2 vols., Paris, 1851).
} 
(MORSE, 1954b: 430). Ao avaliar o período pelos olhos dos românticos, Morse não esconde sua simpatia pela complexidade da visão dos atormentados poetas de meados do século. O problema das últimas décadas do século XIX, em seu entender, foi a euforia acrítica com o crescimento urbano (indústria, comércio, bancos etc.).

Morse concorda com João Camilo de Oliveira Torres que São Paulo estava tão confiante na inevitabilidade de sua evolução que, diferentemente do o Rio de Janeiro, sequer adotou o Positivismo (MORSE, 1954b). De fato, a cidade mudou muito mais que o Rio de Janeiro entre os anos 1850 e 1880, conforme atestaram alguns viajantes. Mas o cenário não era nada linear. Se, em 1855, o pastor protestante norte-americano, reverendo J. C. Fletcher caracterizara São Paulo como "mais intelectual e menos comercial" que a capital do Império, em 1909 o francês Denis afirmou o oposto: “A sociedade de São Paulo é menos inclinada à literatura, à dicção e à eloquência do que o Rio; embora a sintamos como mais ativa, São Paulo não é a capital das letras brasileiras. É apaixonada por questões econômicas" (DENIS, 1928:112, apud MORSE, 1954b:431).

O grau de bacharel, antes carregado de uma áurea, como que incumbido da "responsabilidade de delinear horizontes da vida nacional, não passaria, então, de um nicho na ordem urbana burocrática" (MORSE, 1954b: 431). No início do século XX Mário de Andrade lamentou que os estudantes escritores pós-1880 carecessem da profundidade de seus antecessores: pelo contrário, formavam grupos boêmios e mostravam suas excentricidades em uma poesia lânguida de caráter ornamental. A intelectualidade paulista só teria começado a vislumbrar perspectivas de uma nova arte por volta de 1916, com o advento do Modernismo (ANDRADE, 1942: 16, apud MORSE, 1954b: 434). A adesão de Morse à tese de Mário transparece em estudos posteriores, especialmente no "Multiverso", no qual adotou o Modernismo como marco para a busca da identidade por pensadores latino-americanos e brasileiros.

Neste ensaio da juventude Morse limita-se a dizer que a maioria dos modernistas nasceu a partir de 1890 e foi parte da primeira geração que experenciou São Paulo como uma metrópole desde a infância, sem se identificar com o parnasianismo. A principal tarefa assumida por grande parte deles foi "tentar integrar arte e sociedade, uma vez que a arte do fim do século XIX tinha assumido um sentido de virtuosidade e de isolamento do artista em relação à sociedade" (MORSE, 1954b: 434). Diferentemente da geração de Castro Alves, os modernistas, como os românticos de meados do século XIX, foram artistas integrados em suas comunidades. O que impressionava Morse nesses jovens "não 
era a insolência ou iconoclastia, mas a autoconsciência e o senso de missão" (MORSE, 1954b: 434).

Não foram, contudo, somente os poetas e viajantes teriam visto com suspeita o vertiginoso progresso de São Paulo. O sociólogo brasileiro Gilberto Freyre é também elogiado por Morse por ter feito uma crítica arguta do mero progresso econômico e técnico, por deixar de lado outras dimensões da vida. O pernambucano associava a passagem da monarquia para a república no Brasil à negação da herança afro-portuguesa: nessa ocasião as famílias tradicionais teriam chegado a leiloar suas peças de prata e jacarandá aos estrangeiros, substituindo-as por modismos importados da Europa. Segundo Freyre, os autores clássicos e as humanidades perderam espaço para as disciplinas técnicas e práticas.

Jefferson e Edison em vez de Ulisses, Demóstenes e Cícero. Palavras severas do inglês, como "confiança", "empréstimo de financiamento" e "déficit" foram introjetadas no vocabulário. Falava-se das complexidades abstratas da valorização do café, mas não mais sobre "a valorização do homem brasileiro - do homem e do povo" (FREYRE, 1944: 61, apud MORSE, 1954b: 432).

Nessa atmosfera cultural, Morse conclui que os hobbies se subordinaram ao progresso material, e deixaram de lado uma dimensão da vida cívica da cidade" (MORSE, 1954b). Para além das citações literais ou não, o que quero realçar é que, no livro sobre São Paulo e no ensaio sobre sua interpretação cultural da cidade, o norte-americano recorreu a brasileiros, como Gilberto Freyre, para reforçar sua própria crítica ao progresso material desprovido de uma visão humanista, bem como para justificar o uso e o tratamento de fontes de tipos variados para compor um quadro da "mentalidade" de São Paulo. $^{7}$ Já o conceito de "cidades como arenas culturais" e a tese sobre o Modernismo aqui esboçados foram revisitados por Morse na maturidade, conforme veremos a seguir. ${ }^{8}$

\footnotetext{
${ }^{7}$ Sobre a presença de Gilberto Freyre na obra de Richard Morse ver DOMINGUES, 2012 b.

${ }^{8}$ Morse utilizou o termo posteriormente para explicar, por exemplo, como zonas periféricas tornam-se eventualmente "arenas culturais" mais interessantes (ou mesmo de vanguarda) do que algumas do centro. Isso certamente reverbera outra tese fundamental de Morse: as concepções de centro e periferia tem que ser relativizadas e, ocasionalmente, invertidas.
} 
II

Na segunda metade dos anos 1950 Morse começou sua carreira como professor em Porto Rico. No início da década de 1960 mudou-se de volta para os EUA, primeiro em Nova York, e então na Yale University, em New Haven. Foi um período de assentamento das ideias e da vida profissional de Morse, que coincidiu com a expansão imperialista norte-americana na América Latina, cuja consequência acadêmica foi a ampliação desse campo de estudos nos Estados Unidos e uma política generosa de distribuição de bolsas de estudos, da qual Morse se beneficiou.

Durante as décadas de 1960 e de 1970, Morse dedicou-se com afinco ao estudo das cidades latino-americanas, aprofundando e/ou delineando melhor algumas das intuições esboçadas nos escritos anteriores. A que me parece mais interessante de ser frisada é a importância da filosofia de São Tomás de Aquino enquanto um instrumento heurístico imprescindível para compreender a planificação urbana na região. Esta chave o levou a estudar a filosofia medieval, para a qual Étienne Gilson lhe deu algumas pistas gerais, e o historiador chileno Mario Góngora (1915-1985), do qual se tornou amigo, algumas orientações fundamentais para entender o significado das correntes medievais na América.

Aquino é uma referência fundamental nos dois textos sobre cidades selecionados para perseguir a genealogia das formulações de Morse neste período: "Algumas características da história urbana da América Latina", de 1962, e "Prolegômenos para a história urbana da América Latina”, de 1972.

$\mathrm{Na}$ interpretação cultural de São Paulo encontramos insights de Morse relacionando os estudos urbanos com o tomismo na América hispânica (MORSE, 1954c). Nos dois ensaios acima mencionados, bem como em outros do período, essas conexões são documentadas e aprofundadas. O foco na América hispânica não implicou no desaparecimento do Brasil de suas reflexões: há sempre alguns parágrafos comparativos e sempre muito ilustrativos. Mas não são tantos quanto aqueles dedicados às analogias com os Estados Unidos. Tais comparações, aliadas à perspectiva de longa duração, tornam ainda mais instigantes suas interpretações sobre as singularidades da história urbana da América hispânica.

Se a longa duração é, sem dúvida, um traço da obra de Morse em seu conjunto, foi nos estudos sobre cidades desse período de sua vida que ele retrocedeu mais longe no 
tempo em busca de uma melhor compreensão de seu objeto. No texto de 1962 e especialmente nos "Prolegômenos", de 1972, Morse faz uma revisão de análises sobre as cidades na Antiguidade (Lewis Mumford, Henri Pirene) para melhor dimensionar continuidades e descontinuidades entre a cidade antiga e a cidade renascentista/humanista e colonial, bem como o papel e as singularidades da cidade medieval.

Em “Algumas características da História urbana da América Latina”, de 1962, Morse fornece muitos fatos históricos, inclusive tabelas, para demonstrar suas hipóteses, que davam continuidade aos insights contidos no livro sobre São Paulo. Mas o destaque é para a importância do tomismo para um estudo mais compreensivo da estrutura urbana e de várias cidades na América hispânica. Para tal faz um recuo temporal à Antiguidade clássica e à Idade Média, onde encontrou na filosofia de São Tomás a chave interpretativa para a história urbana na região no período colonial.

Dez anos depois, durante os quais sua produção sobre a temática foi bastante significativa, Morse publicou, em 1972, "Prolegômenos para a História urbana da América Latina”, que eu considero uma obra de transição - uma ponte - entre os escritos da juventude e os da maturidade não apenas por uma questão cronológica, mas pelo fato de apresentar sínteses de estudos anteriores e antecipações de abordagens posteriormente aprofundadas por ele.

Morse destaca duas linhas de investigação que teriam iluminado a trajetória histórica das cidades latino-americanas. A primeira foi a análise comparativa das cidades antigas, das tensões entre a polis e a cidade universal e da oposição entre as concepções medievais de Cidade dos homens e de Cidade de Deus. A outra foi uma revisão das origens da cidade medieval na Península Ibérica comparando-as com as do resto da Europa Ocidental. A partir delas sugeriu que "essas duas linhas de investigação poderiam ser entrelaçadas a partir do pensamento social e político de São Tomás de Aquino e de sua influência dominante nos países ibéricos até o século XVII” (MORSE, 1972: 361). Seu pressuposto é que: “As ideias tomistas beberam generosamente nas tradições antigas: na teologia patrística, especialmente a agostiniana, marcada pelo idealismo neoplatônico e pelo estoicismo romano; na lei romana, reavivada em Bologna no final do século XI; e no novo aristotelismo" (MORSE, 1972: 392).

A proposta do pensamento político de São Tomás, prossegue ele, era reconciliar as convicções sobre a vida cívica com aquelas concernentes à salvação pessoal; ou seja, unir Aristóteles a Santo Agostinho. Tomás teria incorporado de Agostinho a ideia de que a pessoa humana é feita à imagem de Deus. Pelo fato de o ser humano estar ligado 
imediatamente a um exemplar fora da ordem do universo, nada mais plausível do que a possibilidade de encontrar salvação fora do grupo ao qual pertence. Ao mesmo tempo, Tomás assimilou de Aristóteles "o ensinamento de que a virtude é essencialmente social: que todo ato humano é um ato político e que o homem se completa no serviço à comunidade” (MORSE, 1972: 393).

São Tomás, como Aristóteles, via os arranjos da comunidade política, a "Cidade Cristã", como amplamente forjados pela arte (indústria): seus princípios eram fundamentados na natureza humana. Consequentemente, a lei positiva deveria seguir a lei natural. Segundo Morse, o De Regimine Principum, de São Tomás, com seus preceitos aristotélicos, influenciou diretamente os tratados medievais espanhóis sobre cidades e, através deles, as ordenanças colonizadoras espanholas para as Índias. Mas o que ele queria compreender era por que o conceito tomista de corpo político encontrou recepção tão conveniente ao sul dos Pirineus. E, depois, na América colonizada por eles. A resposta, em seu entender, residia no caráter urbano ibérico e de sua expansão na América.

Morse concorda com a tese de Ernest Troeltsche, que afirma que, ainda que o pensamento católico tenha adquirido uma conotação rural séculos mais tarde, na época do Romantismo e da Restauração do século XIX sua vocação era urbana:

É apenas a cidade que São Tomás leva em conta. Em sua visão, o homem é naturalmente um morador da cidade, e ele considera a vida rural apenas como o resultado de infortúnio ou do querer; a cidade sobre a qual ele reflete é, em si, fortemente agrária e suporta sua própria vida por um sistema de troca ordenada de mercadorias com o campo ao redor, que está sob seu mando (TROELTSCH, Ernst, apud MORSE, 1972: 394).

Para Morse, independente da forma como se credita o modelo de pensamento social de São Tomás, a hospitalidade ibérica ao ideal do regime urbano reflete as exigências da ordem política e institucional. Dentre elas destaca o não florescimento pleno do feudalismo durante a Reconquista, como já sobejamente reconhecido por Sánchez Albornoz e outros. A colonização era nucleada ao redor dos centros agráriourbanos, e não das unidades senhoriais de produção. "Os homens da cidade e os trabalhadores rurais eram relativamente desincumbidos de obrigações servis, ainda que o patriciado urbano fosse senhorial, e não mercantil" (MORSE, 1972: 394). Em suma, a sociedade estava impregnada com memórias de seu passado evangélico. 
O fato de o esquema tomista ser eminentemente apropriado a tal cenário explica parcialmente sua longa carreira na Península Ibérica, onde recebeu sua mais detalhada e perspicaz aplicação às grandes questões da época, incluindo a administração das colônias americanas (MORSE, 1972: 394).

Nesse processo, o tomismo ajudou a revitalizar nas mentes ibéricas certas perspectivas da antiguidade mediterrânea, que corresponderiam a um mundo com o qual a continuidade fora desgastada através dos séculos, mas nunca completamente rompida. Morse está menos em busca de continuidades históricas do que em analogias entre a antiguidade, a Idade Média, a Ibérica e a América hispânica. Sua tese é que:

Assim como as antiquíssimas categorias da Política de Aristóteles iluminam os processos internos do regime urbano da América Latina, o exemplo do legionário posto avançado romano nos ajuda a caracterizar as relações externas, políticas e ecológicas, das pequenas cidades latino-americanas. A localização da colônia romana (referência a colere, cultivar) ou da pequena cidade do Novo Mundo era ditada mais por considerações políticas, estratégicas e agrícolas que por questões comerciais ou industriais (MORSE, 1972, 372)

Ao analisar cidades antigas, medievais e modernas (coloniais) nos Prolegômenos, Morse sugeriu que talvez fosse menos interessante para o historiador buscar continuidades na história do que estabelecer analogias.

A discussão comparativa entre cidades antigas e latino-americanas é problemática porque, em certos pontos, não se pode afirmar inequivocamente se há uma continuidade histórica direta, se a questão é estritamente uma analogia histórica ou se, talvez, estaríamos lidando com um caso isolado de réplica histórica dentro da área cultural mediterrânea. Para dar forma e ancoragem mais firmes às impressões sugeridas acima, consideraremos agora o desenvolvimento de instituições municipais na Europa ocidental durante os séculos que precederam a descoberta da América. Ao fazê-lo, estamos abandonando a tática de analogia seletiva de cruzamento temporal para empreender a reconstrução de dois padrões de desenvolvimento urbano que 
se desdobraram, simultaneamente, ao norte e ao sul dos Pirineus (MORSE, 1972: 373).

Isso é o que ele buscou nos "Prolegômenos": elencar e agregar várias teses presentes em ensaios anteriores, como em "Algumas características da história urbana da América Latina" e, como o título sugere, oferecer os princípios gerais, ou uma introdução ao estado geral da arte dos estudos urbanos na América Latina. Ou seja, este estudo sistematiza suas análises anteriores e teoriza sobre elas, ainda que o suporte factual seja tão ou mais presente quanto em outros ensaios das décadas de 1960 e 1970.

É também impressionante como ele antecipa temas e perspectivas fundamentais no Espelho, obra mais conhecida e discutida de Morse no Brasil no fim da década de 1980 e durante as seguintes. Um exemplo no qual podemos notar generalizações que repercutem no Espelho é na comparação entre as cidades da Hispano-América e as da América puritana, que emergem aqui como modelos, ou tipos. É também digna de nota a análise das singularidades das cidades da Idade Média e da Idade Moderna ibérica: ao assinalar certas continuidades com a Antiguidade, a intenção declarada de Morse é estabelecer analogias históricas, um recurso que foi amplamente utilizado em seus escritos da maturidade.

Em suma, "Algumas características" e "Prolegômenos" me parecem ensaios que documentam, exemplificam e complementares das teses de Morse sobre a importância do tomismo e da análise comparativa de longa duração. O tomismo serve aqui como a chave para oferecer um quadro detalhado da história urbana da Idade Média Ibérica, tanto na Espanha quanto em Portugal.

Se na juventude a cidade selecionada foi São Paulo, nesses ensaios não é possível precisar uma cidade: a história e cultura urbanas na América hispânica são tomadas em uma perspectiva de conjunto, e em um prazo muito mais dilatado do que no estudo sobre a capital paulista. Os textos começam com a cidade antiga para chegar às cidades americanas. Morse exibe erudição e elegância em seu diálogo com estudiosos das cidades na Antiguidade, na Idade Média, no Renascimento e no Novo Mundo. Demonstra conhecer bem a história antiga (urbana ou não), em especial as obras dos clássicos, o que lhe facilita a tarefa de estabelecer as conexões que se seguem.

Em especial nos "Prolegômenos" ficamos cientes da importância de se compreender a cidade medieval para entender os desdobramentos das cidades europeias na América. Mas ele não pula simplesmente de uma para outra: entre elas está a cidade 
renascentista na Europa, que agrupa em dois modelos: as da Europa do Norte e as da Ibéria. Elas seriam como que duas formas de "devoração" da tradição antiga e medieval que foram trazidas, respectivamente, para a América do Norte e para a América espanhola. Trata-se de um tema bastante complexo, que ele desenvolve melhor no Espelho de Próspero (1988), mas também, em certa medida, nos ensaios da década de 1990, que analiso a seguir.

III

Os ensaios "Cidades periféricas como arenas culturais" (1995b) e "Cidades como pessoas" (1992) se complementam e ilustram a retomada por Morse, na maturidade, da temática urbana de forma mais teórica e, no caso do primeiro, lidando com cidades que extrapolam o mundo americano. Se no período anterior Morse traçava analogias entre as cidades coloniais americanas, as da Idade Média e as do Renascimento, em "Cidades "periféricas"” toma como parâmetro algumas cidades europeias no final do século XIX. Esse foi o seu único texto traduzido para dois idiomas (MORSE, 1984). ${ }^{9}$

Em “Cidades periféricas” Morse toma os exemplos de Viena e de São Petersburgo em busca de pistas para melhor entender a América Latina. A opção por elas se deve ao fato de serem cidades que, localizadas na periferia da Europa, se destacaram, na virada do século XIX para o século XX, como "arenas culturais" de vanguarda em comparação com outras cidades no centro do capitalismo europeu. Esses exemplos ajudam a dar substância aos insights esboçados no ensaio sobre São Paulo, de 1954, em que analisava a situação da cidade na segunda metade do século XIX e no início do século XX. Sua tese havia sido que a situação periférica da capital paulista em relação ao Rio e a Salvador

\footnotetext{
${ }^{9}$ Em 1984 Morse publicou “'Peripheral' Cities as Cultural Arenas (Russia, Austria, Latin America)", que foi quase que imediatamente traduzido para o espanhol: Ciudades 'periféricas' como arenas culturales (Rússia, Austria, América Latina) MORSE \& HARDOY, Jorge Enrique (compiladores). Cultura urbana latino-americana. Buenos Aires/Argentina: Consejo Latinoamericano de Ciencias Sociales. $1^{a}$ edición, 1985, 39-62 (tradução de Ernesto Leibovich). Dez anos depois saiu em português: Cidades 'periféricas' como arenas culturais: Rússia, Áustria, América Latina. Revista Estudos Históricos. Rio de Janeiro; FGV, v. 8, n.16, 1995, 205-225. No interim entre o original e a tradução para o português, Morse já havia publicado, em inglês, "Cidades como pessoas". A história de São Paulo foi publicada em inglês e português (duas edições). O Espelho em espanhol e português; O Nem World Sounding em inglês e português (A volta do MacLuhnaíma); “O Multiverso" em inglês e português. É interessante notar certa inversão de interesse pela obra de Morse no México e no Brasil. Tanto o Espelho quanto o ensaio sobre as cidades periféricas foram publicados em espanhol bem antes do que em português: respectivamente seis e dez anos. Mas nem New World Sounding nem "Multiverse" foram traduzidos até o momento para o espanhol.
} 
talvez tivesse contribuído para que a cidade se tornasse uma arena cultural e o centro do Modernismo.

Foi precisamente essa tese que tornou-se o fio condutor de "Cidades periféricas como arenas culturais" (1995b), e posteriormente do mais robusto ensaio da maturidade de Morse, "O multiverso na busca da identidade na América Latina” (2011), no qual alertava para a multidiversidade na busca de uma identidade na América Latina. E o parâmetro de comparação foi justamente a "Europa subdesenvolvida", para utilizar uma expressão de Marshall Berman adotada por Morse (BERMAN, 1982; MORSE, 2011). As reflexões de do humanista/marxista norte-americano Marshall Berman (1940-2013) e do historiador alemão Carl Schorske (1915-2015) sobre as especificidades da modernização da Alemanha e em outras cidades periféricas da Europa na segunda metade do século XIX foram fontes de inspiração para a interpretação de Morse sobre as singularidades da cultura urbana e sobre a problemática da identidade na América Latina. Segundo Morse, foi com o Modernismo das primeiras décadas do século XX que a América Latina começou de fato a formular criticamente sua problemática identidade (MORSE, 2011). Isto não quer dizer, contudo, que antes dele não tenham existido tentativas isoladas, ou que até então, a "periferia" se limitasse a emular o "centro".

Pelo contrário, Berman argumenta que, desde o século XIX, algumas "áreas periféricas" da Europa - fossem países que ainda estavam se unificando, como era o caso da Alemanha e da Itália, ou nas "fronteiras da Europa" (Rússia) - haviam propiciado parâmetros para uma reflexão sobre sua situação frente à modernidade ocidental. Morse retoma a argumentação de Berman como ferramenta para analisar a problemática urbana da América Latina em "Cidades periféricas" (1995b) e a questão da busca da identidade no "Multiverso" (2011). ${ }^{10}$

Em “Cidades periféricas” Morse analisa as cidades “periféricas” da Rússia, Viena e América Latina como arenas culturais recorrendo à tese de Berman sobre a "experiência da modernidade" na periferia próxima da Europa, como uma forma de melhor entender as cidades latino-americanas. Como Berman, Morse localiza na Alemanha da segunda metade do século XIX uma tensão entre a atração pelas reformas econômicas e políticas da Europa ocidental e o sentimento de que uma nação "germano-cristã" poderia se projetar com seus próprios valores, renegando aqueles tidos como universais. A limitação

\footnotetext{
${ }^{10}$ Morse explicita, no texto originalmente publicado em 1984, que estava testando algumas hipóteses que estavam sendo mais desenvolvidas em um artigo de mais fôlego, que só concluiu em 1995 (Multiverso), vertido para o português em 2011.
} 
da interpretação de Berman, segundo Morse, residia no marxismo: ainda que fosse crítico do capitalismo, não rompia com a ideia de universalidade e evolução (expressa em sua noção marxista de etapas históricas). O desafio que Morse sentia ter diante de si era diferente: "as sociedades periféricas enfrentam necessariamente a pulverização de suas heranças? Todas as cidades modernas devem parecer com Paris e Nova Iorque e pensar como elas?" (MORSE, 1995b: 15). Naturalmente sua resposta era negativa.

Outro estudo acionado por Morse em “Cidades periféricas” foi o de Carl Schorske sobre Viena no fim do século XIX (1988): originalmente publicado em 1961, já tratava de forma comparada a 'periférica' Viena e as modernas Paris e Londres. Viena foi alvo de muitos estudos, pois parecia preocupante que a capital de um Império fosse incapaz de seguir a locomotiva do progresso, de assimilar um ethos burguês e de produzir uma psicologia de casse média (JANIK \& TOULMIN, 1973). Segundo Schorske, a vida literária vienense carecia do espírito antiburguês dos franceses ou do meliorismo dos ingleses. Não é que fossem engajados ou desengajados; apenas viam o imperador como um pai protetor; como não tinham poder independente buscavam proteção na aristocracia. Daí a preeminência do antissemitismo, da opereta e da psicanálise que revelariam a fuga da burguesia frustrada para o passado mágico e revelador (SCHORSKE,1988). Como consequência do fracasso da política liberal, a cultura tornou-se uma expressão, e não uma fonte de valores. Ocorreu também uma revolta contra a razão expressa em movimentos de massa, como foi o caso do pangermanismo. O desafio dos intelectuais vienenses parecia-lhe ser como se libertar da opressão em várias formas imposta à cidade, sendo Wittgenstein o mais representativo entre deles.

Para Morse, Viena de Wittgenstein e a Petersburgo de Dostoievsky mostram como cidades com urbanização insuficiente podem inspirar importantes movimentos de vanguarda. O que não dizer então, questiona-se, da distante América Latina? Não seria a região profética para oferecer mensagens ao centro ao mesmo tempo em que estabelecem suas próprias questões frente aos dilemas da modernidade? ${ }^{11}$

Apesar da tentação pelo diagnóstico de semelhanças entre a periferia europeia e a América Latina, Morse acentua também diferenças importantes. É especialmente interessante o contraste estabelecido por ele entre a 'cidade abstrata e intencional' de Dostoievsky e a cidade também intencional, porém geométrica, fundada pelos espanhóis

\footnotetext{
${ }^{11}$ Segundo o poeta mexicano Octavio Paz $(1956,1986)$, muito admirado por Morse, a América Latina estava "condenada à modernidade". O dilema era que tipo de modernidade abraçar, ou como se incluir em um tempo histórico do qual havia sido excluída desde sua descoberta.
} 
no Novo Mundo desde o início do século XVI. Essas cidades, vilas e missões, seja sob o ponto de vista político, social, econômico ou eclesiástico não tinham nada de abstrato, ainda que estivessem longe de se constituir na versão concreta do planejamento da cidade ideal. ${ }^{12}$ Outra diferença seria no campo musical. Enquanto Viena passava pela transição da música aristocrática de Mozart e Beethoven para a era burguesa das grandes sinfonias, "a América Latina, apesar da fertilidade de sua cultura musical informal, não dispunha das condições sociológicas necessárias, quando não suficientes, para a inspiração sinfônica" (MORSE, 1984: 210). Uma prova, contudo, de que os latino-americanos não eram consumidores passivos foi a recepção do Fausto de Gounod em Buenos Aires em 1866. ${ }^{13}$

Em 1992 foi publicado, em inglês, "Cidades como pessoas" (1992), um ensaio no qual Morse retomou a temática urbana que não aparecera desde 1984, em "Cidades periféricas". Uma importante singularidade desse ensaio reside no fato de ter sido o último estudo do autor sobre a temática das cidades, em que retoma sinteticamente vários pontos analisados nas décadas anteriores.

Em "Cidades como pessoas", originalmente um capitulo de um livro editado por ele mesmo e por Jorge Hardoy - Rethinking the Latin American City, de 1992 -, Morse se colocou como desafio prover o contexto histórico para o tema central do volume: repensar as cidades latino-americanas. Sua sugestão foi identificá-las como atores sociais, seguindo a trilha de José Luís Romero. “As cidades assim representadas - aristocráticas, crioulas, patrícias, burguesas ou massificadas - podem ser tratadas mais como representantes do que criadores de uma ordem social, ou como exemplares, ao invés de agentes de mudança urbana" (MORSE, 1992: 4). Aqui ele mesmo oferece uma genealogia de seus estudos na área: "ao armar a cena para os capítulos que se seguem e ao oferecer um contexto histórico para o tema central de "Cidades como pessoas", recorrerei a um bom número de meus ensaios anteriores, adaptando-os à ocasião presente”. Ele entrelaça, então, os contrastes feitos em seus vários ensaios entre cidades das Américas Latina e da

\footnotetext{
${ }^{12}$ Sobre esta temática da cidade ideal em contraposição à cidade real, ver especialmente:

RAMA, Ángel. A cidade das letras. São Paulo: Brasiliense, 1985 e HOLANDA, Sérgio Buarque. Raízes do Brasil. Rio de Janeiro: José Olympio, 1994.

${ }^{13}$ A versão de Fausto do francês Charles Gounod, baseada no livreto de Carré intitulado "Fausto e Marguerita" é livremente inspirada na de Goethe e estreou em Paris em 1859. Na ocasião a recepção não foi favorável, mas em 1862 uma reapresentação fez dela um grande sucesso, sendo traduzida para 25 línguas, inclusive o espanhol. Sua utilização por Morse visa confirmar a força e capacidade da literatura de registrar a complexidade da cidade e da cultura latino-americana. O Fausto do poeta argentino Estanislao del Campo (1834-1880) é um bom exemplo da sintonia e criatividade de uma "arena periférica" se apropriando da cultura do "centro" (DOMINGUES, 2012).
} 
América do Norte com as reflexões da maturidade sobre as problemáticas relações entre centro e periferia para asseverar que: "As cidades norte-americanas (e, por extensão, as cidades do Ocidente industrial), outrora modelo para emulação na América Latina, cumprem, hoje, a função igualmente importante de anti-modelo" (MORSE, 1992: 4).

Este texto oferece um diálogo harmonioso entre psicologia (psicanálise), sociologia e literatura ao comparar as cidades com pessoas, um pressuposto cujo insight já estava no trabalho sobre São Paulo de 1954. A tese de Morse era de que, após 1920, os intelectuais latino-americanos quebraram o molde positivista de seus antecessores para conceber formas mais particulares e imaginativas de ver o fenômeno urbano. Dentre eles, ocupa lugar de destaque a obra de Gilberto Freyre, por sua reconstituição da vida rural e patriarcal dentro do domínio urbano do século XIX.

Em Sobrados e Mucambos (1936) o autor teria rompido com a centenária denúncia da herança ibérica, para estabelecer uma posição relativista que rendeu explicações mais ricas para a lógica das instituições urbanas. Ele demonstrou especial sensibilidade nas correspondências estabelecidas entre a forma física da cidade brasileira - sua arquitetura particular e espaços públicos - e sua organização social em mudança (MORSE, 1992: 13). ${ }^{14}$

Para Freyre, prossegue Morse, o coração da sociedade urbana era o "patriarcado urbano", cuja decadência ele narrou "com riqueza de detalhes e com nostálgica condescendência". Mais do que com a urbanização (sociológica, política e econômica), Freyre lidou com a "cidadeficação" (social, cultural, de atitude). A cidade brasileira, em sua obra, "era um veículo, não um motor para a mudança. E os seus habitantes eram atores, não agentes".

No entanto, se Freyre falhou em transmitir uma sensação de dialética implacável da história na era capitalista, sua paciência com as minúcias da experiência humana tornou a sociedade urbana visível, dando ao intelecto um suporte renovado após o interregno positivista. De forma muito pessoal, ele domesticou a cidade ocidental nos processos do mundo ibérico (MORSE, 1992: 14).

\footnotetext{
${ }^{14}$ Uma correlação similar perpassou os textos morseanos sobre as cidades latino-americanas escritos nas décadas de 1960 e 1970, ainda que não mencionassem Freyre.
} 
A força do fator psicológico, ou psicanalítico, atribuído por Morse a Gilberto Freyre já vinha de longo tempo. Diria que desde uma resenha sobre Ingleses no Brasil de 1949. Mas foi em um texto sobre os brasilianistas, em 1983, que Morse cunhou a expressão freudiano manqué. Ele elogia, em Freyre, a abordagem psicológica em diálogo com a sociologia, tomadas como parâmetro para avaliar outros autores latino-americanos, com destaque para o argentino Ezequiel Martínez Estrada. Em X-Ray of the Pampa (1933) e La cabeza de Goliat (1940), Martínez Estrada, como Freyre, recorreu à psicanálise para elaborar sua análise de Buenos Aires. Para ambos, conectar-se com a cidade moderna significava aceitar sua história ao invés de propor uma agenda de "reformas" práticas. "Essa história parecia a Freyre relativamente benigna e capaz de oferecer diretrizes culturais para a adaptação da vida e das instituições urbanas ao mundo contemporâneo. Essas sugestões se tornaram explícitas em seus estudos sobre a "luso-tropicologia" (MORSE, 1992: 15).

O que Morse quer salientar é que Martinez Estrada considerava a história da Argentina opressiva porque havia sido suprimida dos argentinos. Daí sua cidade moderna carecer de estrutura, forma ou força espiritual. Somente trazendo à consciência os fantasmas do passado, insistia Estrada, poder-se-ia exorcizá-los para que os argentinos pudessem viver juntos, saudavelmente. Comparando Buenos Aires e a Argentina com um ser humano, Morse entende que isso implicaria em recuar da história do mundo exterior para ampliar imagens e obsessões da psique privada. Ou seja, ir para divã. Porém, ao invés de projetar suas próprias obsessões sobre a nação, à maneira autoindulgente de Freyre, Martínez Estrada teria optado por analisar a mente da coletividade. Daí resultou uma, segundo Morse, uma imagem de Buenos Aires como uma "ilusão onírica" da Argentina:

Martínez Estrada teria descrito uma metrópole cujos habitantes viviam na periferia da Europa; olhar para o "interior" era, para eles, olhar para o estrangeiro. Imergiu o leitor em um cenário onde tanto o passado colonial quanto o presente faziam parte de um mundo pré-histórico - enfeitado de fantasias e resistindo a processos ordeiros de evolução. Buenos Aires era "a ilusão onírica da Argentina, era uma cabeça de Golias cortada; não a capital de uma nação, mas apenas de si mesma, uma criatura teratológica condenada a viver só e não para sua espécie" (MORSE, 1992: 14). 
Martinez Estrada e Freyre foram retomados por Morse "O multiverso da busca da identidade latino-americana entre 1920 e 1970” (2011), publicado em inglês em 1995, desta vez comparados com outros autores em busca de uma identidade na América Latina. Neste longo ensaio em que traça uma genealogia da busca pela identidade na América Latina entre 1920 e 1970, as cidades latino-americanas, no entender de Morse, continuam a se comportar como pessoas e como arenas culturais de vanguarda. Dentre elas destaca, nos anos 1920, as cidades de São Paulo, Buenos Aires e do México. Em cada uma delas Morse seleciona dois pares de modernistas: Mário e Oswald de Andrade em São Paulo, Jorge Luís Borges e de Robert Artl em Buenos Aires, e Alfonso Reys e Ezequiel Martínez Estrada na Cidade do México. Eles teriam, a seu ver, pontos em comum e importantes diferenças. Cada um deles expressaria vertentes singulares dos seus respectivos modernismos - brasileiro, argentino e mexicano - que, no entender de Morse, passam pela leitura das cidades em que viveram e conheceram, ainda que não com a mesma intensidade ou perspectiva.

O "Multiverso", a meu ver, repõe a pergunta feita em "Cidades Periféricas", adaptada à temática da busca pela identidade: em que medida o estudo de casos de desenvolvimento tardio na periferia da Europa e no Japão, que empreendiam uma busca pela identidade na segunda metade do século XIX, podem iluminar a problemática da busca da identidade na América Latina no mesmo período? (MORSE, 1995b: 4-6). Morse abraça a caracterização, por Marshall Berman, da Alemanha como um país europeu "subdesenvolvido" no século XIX para melhor entender tanto as cidades quanto a busca pela identidade na América Latina.

\section{Conclusão}

Um importante ponto a ser destacado neste percurso genealógico da temática das cidades na obra de Morse é o fato de ele ter redigido "Multiverso", "Cidades Periféricas" e "Cidades como pessoas" contemporaneamente. Em "As cidades 'periféricas' como arenas culturais", originalmente publicado em 1984, ele chega a explicitar, em nota de rodapé, que as ideias ali "ensaiadas" eram como que balões de ensaio, como insights, para 
algumas teses mais detalhadamente desenvolvidas em "The Multiverse of Latin American Identity, c. 1920-c. 1970" (1995a). ${ }^{15}$

Em comum entre os dois ensaios há também um pressuposto metodológico: todas as comparações estabelecidas por Morse entre cidades da periferia da Europa e da América Latina baseiam-se em narrativas literárias e/ou filosóficas sobre elas: a Petersburgo de Dostoievski, a Viena de Freud e Wittgenstein, o Rio de Machado de Assis, a Buenos Aires de Jorge Luís Borges e de Robert Artl. ${ }^{16}$

Morse não se identifica com o evolucionismo marxista ou com a abordagem da “cultura das cidades” tal qual efetuada, por exemplo, por Lewis Mumford, (MUMFORD, 1961). Pois não lhe interessa o desenvolvimento urbano tal qual descrito ou analisado, mas sim como experimentado e compartilhado. O que ele quer mesmo questionar é a visão de "periferia" como capaz somente de dar respostas miméticas ao "centro": está em busca de contracorrentes e de mensagens alternativas. E é partir dessas premissas que Morse estabelece um instigante contraponto entre algumas visões da cidade ocidental desde o Romantismo até o Modernismo comparando três "tipos" de cidades: Paris (e Londres) no "centro"; Petersburgo e Viena na "periferia imediata"; Rio de Janeiro e Buenos Aires na "periferia distante".

Sua tese é que Petersburgo e Viena funcionam como resistências que talvez possam descartar, incendiar ou metamorfosear a inspiração modernista europeia. O mais importante para seu estudo, contudo, era o fato delas sugerirem pré-condições para o Modernismo na América Latina, que poderia, e fez uma ressignificação semelhante, porém mais radical da cultura europeia. Em fins do século XIX o "dantesco" Rio de Janeiro de Machado de Assis, por exemplo, diferentemente do Petersburgo de Dostoievski, era confusamente cético em relação à modernidade (MORSE, 2011). Já nos anos 1920, as cidades modernistas da América Latina (São Paulo, Buenos Aires e Cidade do México) enfrentaram de frente a problemática da modernidade ocidental sem temores de serem devoradas por ela: a atitude então assumida foi de devorá-la, conforme proposto pelo movimento antropofágico de São Paulo (MORSE, 2011; DOMINGUES, 2011). ${ }^{17}$

\footnotetext{
15 É importante esclarecer que Morse começou a redigir o "Multiverse" em 1975, a convite de Leslie Bethell, para a coleção Cambridge History of Latin America, só concluindo-o 20 anos depois. A história da elaboração deste ensaio foi documentada e comentada por Bethell (2010).

${ }^{16}$ Também neste aspecto vale assinalar as semelhanças com Marshall Berman e Carl Schorske, que se valem amplamente de fontes literárias.

${ }^{17}$ O latino-americanista Gerald Martin (1998) concorda com a avaliação de Morse sobre a singularidade dos modernismos latino-americanos em relação aos europeus e ao norte-americano.
} 
A rigor, Morse não acredita que qualquer cidade - nem mesmo Paris - contenha todos os elementos de um temperamento moderno. Mesmo na 'Cidade Luz' assinala que o Modernismo nas artes e nas letras - definível em parte como um assalto às contradições da modernidade - não era reconhecível pelos consumidores parisienses, que tinham uma concepção de passado cumulativa e mesmo alucinatória e para os quais a novo era a última palavra. Ou seja, não havia em Paris qualquer obsessão com a identidade nacional, como foi o caso da periferia da Europa no fim do século XIX e da América Latina no início do XX. Daí a sua opção por tomar como parâmetros cidades europeias periféricas que pudessem iluminar o caso latino-americano.

\section{Fontes}

MORSE, Richard M (2011). O multiverso na busca pela identidade na América Latina desde 1920 até 1970. In: BETHELL, Leslie. A América Latina após 1930: ideias, cultura e sociedade. São Paulo: EDUSP. (Coleção: História da América Latina. v. VIII), pp. 19-160.

(1995a). The Multiverse of Latin American Identity, c. 1920-c. 1970. The Cambridge History of Latin America, vol. 10, edited by L. Bethell. New York: Cambridge University Press, pp. 1-129.

(1995b) As Cidades 'Periféricas' como arenas culturais: Rússia, Áustria e América Latina. Revista Estudos Históricos, Rio de Janeiro, vol. 8, no 16pp. 205-225.

(1992). Cities as People. In: MORSE, Richard; HARDOY, Jorge (Ed.). Rethinking Latin American City. Washington/Baltimore/London: The Wilson Center Press/The John Hopkins University Press, pp. 3-19.

(1990). A volta de McLuhanaíma: Cinco estudos solenes e uma brincadeira séria. São Paulo: Companhia das Letras.

(1984). "Peripheral" Cities as Cultural Arenas (Russia, Austria, Latin America)", Journal of Urban History, Aug., pp.423-462.

(1983). Brazilianists, God Bless Them! What in the World is to be Done? Occasional Papers on Latin America Studies, Stanford / Berkeley, n. 5, pp. 219231, winter.

(1972). A Prolegomenon to Latin American Urban History. The Hispanic American Historical Review, v. 52, n. 3, pp. 359-394, ago..

(1954a). De comunidade a metrópole: biografia de São Paulo. Tradução Maria Aparecida Madeira Kerbeg. São Paulo: Comissão do IV Centenário.

(1954b). São Paulo since Independence: A Cultural Interpretation. The Hispanic American Historical Review, v. 34, n. 4, pp. 419-444, nov.

(1954c). Towards a Theory of Spanish American Government. Journal of the History of Ideas, v. 15, n. 1, pp. 71-93, jan..

(1949). Ingleses no Brasil: aspectos da influência Britânica sobre a vida, a paisagem e a cultura do Brasil by Gilberto Freyre. The Hispanic American Historical Review, v. 29, n. 4, pp. 609-611, nov. 


\section{Referências Bibliográficas}

BERMAN, Marshall (1982). Tudo que é solido desmancha no ar. A aventura da modernidade. São Paulo: Companhia das Letras.

BETHELL, Leslie. Richard Morse e a Cambridge History Of Latin America. In: DOMINGUES, Beatriz H \& BLASENHEIM, Peter L (Orgs.). O código Morse. Ensaios sobre Richard Morse. Belo Horizonte: Editora UFMG, 2010.

CANDIDO, Antonio (1980). Teresina etc. Rio de Janeiro: Paz e Terra. (1988). Prefácio. In: MORSE, Richard. O espelho de Próspero: Cultura e ideias nas Américas. São Paulo: Companhia das Letras, pp. 9-12.

CASTRO, Ana Cláudia Veiga de (2010). Dois autores em busca de um passado: Richard Morse e Sergio Buarque na construção da especificidade paulista. Seminário de História da Cidade e do Urbanismo, v. 11, n. 3, pp. 1-16.

(2013). Um americano na metrópole [latino-americana]: Richard Morse e a história cultural urbana de são Paulo 1947-1970. 2013. 364 p. Tese (Doutorado em História e Fundamentos da Arquitetura e Urbanismo) - Faculdade de doutorado defendida na Faculdade de Arquitetura e Urbanismo da Universidade de São Paulo, São Paulo.

DOMINGUES, Beatriz H \& BLASENHEIM, Peter L (org.) (2010). O código Morse. Ensaios sobre Richard Morse. Belo Horizonte: Editora UFMG. (2011). História e Literatura na busca pela identidade na América Latina no século XX: a visão de Richard Morse. In: História da Historiografia. Vol. 7, pp. 174-199. (2012a). Do Fausto de Goethe ao Fausto de Estanislao del Campo: cidades e identidades em "arenas periféricas" da Europa e da América Latina em fins do século XIX. In: FERNANDES, Luis Estevam de Oliveira (org.). História da América: historiografia e interpretações. Outro Preto: Editora UFOP, pp. 274-286. (2012b). Estrangeiros e visionários: Morse, Tocqueville e os Estados Unidos. Interseções, Rio de Janeiro, v. 14, n. 2, pp. 268-298, dez.

DUMONT, Louis (1985). O individualismo: uma perspectiva antropológica da ideologia moderna. Rio de Janeiro: Rocco.

HOLANDA, Sérgio Buarque (1994). Raízes do Brasil. Rio de Janeiro: José Olympio.

JANIK, Allan \& TOULMIN, Stephen (1973). Wittgenstein's Vienna. New York: Simon and Schuster.

MARTIN, Gerald (1998). Narrative since 1920. In: BETHEL, Leslie (org.). A Cultural History of Latin America: Literature, Music and Visual Arts in the 19th and 20th Century. Cambridge: Cambridge University Press, pp.907-925.

MUMFORD, Lewis. (1998 [1961]). A Cidade na História - suas origens, transformações e perspectivas. São Paulo: Martins Fontes Editora.

PAZ, Octavio (1986). O labirinto da solidão e post-Scriptum. Rio de Janeiro: Paz e Terra. RAMA, Ángel (1985). A cidade das letras. São Paulo: Brasiliense.

SCHORSKE, Carl E (1988). Viena fin-de-sciècle: política e cultura. São Paulo/Campinas: Cia das Letras/Ed. Unicamp.

Artigo recebido em 20 de outubro de 2016.

Aprovado em 21 de novembro de 2016. 